\title{
GEOMETRICALLY CONVEX FUNCTIONS AND ESTIMATION OF REMAINDER TERMS FOR TAYLOR EXPANSION OF SOME FUNCTIONS
}

\author{
XiAOMING ZHANG AND NingGUO ZHENG
}

Abstract. In this paper, we establish two integral inequalities for geometrically convex functions. As consequences, we get the estimation for remainder terms of Taylor series for $e^{-x}, \sin x$ and $\cos x$.

Mathematics subject classification (2010): 26D15, 26D10.

Keywords and phrases: Inequality, geometrically convex function, remainder term.

\section{REFERENCES}

[1] P. Montel, Sur les functions convexes et les fonctions sousharmoniques, Journal de Math., 9, 7 (1928), 29-60.

[2] C. P. Niculescu, Convexity according to the geometric mean, Math. Inequal. Appl., 3, 2 (2000), $155-167$.

[3] C. P. Niculescu And L-E. Persson, Convex Functions: Basic Theory and Applications, Universitaria Press, Craiova, 2003.

[4] X.-M. Zhang, Y.-M. ChU, The geometrical convexity and concavity of integral for convex and concave functions, Int. J. Mod. Math., 3, 3 (2008), 345-350.

[5] X.-M. Zhang, Y.-M. Chu, New Discussion to Analytic Inequalities, Harbin Institute of Technology Press, 2009. (Chinese) 